Sādhanā Vol. 38, Part 3, June 2013, pp. 527-541. (c) Indian Academy of Sciences

\title{
Kinetics of borided gear steels
}

\section{IBRAHIM GUNES}

Department of Metallurgical and Materials Engineering, Faculty of Technology, Afyon Kocatepe University, 03200, Afyonkarahisar, Turkey

e-mail: igunes@aku.edu.tr

MS received 13 October 2012; revised 26 January 2013; accepted 7 February 2013

\begin{abstract}
In this study, the case properties and diffusion kinetics of GS18NiMoCr36 (GS18), GS22NiMoCr56 (GS22) and GS32NiCrMo6.4 (GS32) gear steels borided in Ekabor-II powder were investigated by conducting a series of experiments at temperatures of 1123,1173 and $1223 \mathrm{~K}$ for 2,4 and $6 \mathrm{~h}$. The boride layer was characterized by optical microscopy, X-ray diffraction technique and microVickers hardness tester. X-ray diffraction analysis of boride layers on the surface of the steels revealed the existence of $\mathrm{FeB}, \mathrm{Fe}_{2} \mathrm{~B}, \mathrm{CrB}$ and $\mathrm{Cr}_{2} \mathrm{~B}$ compounds. The thickness of the boride layer increases by increasing boriding time and temperature for all steels. The hardness of the boride compounds formed on the surface of the steels GS18, GS22 and GS32 ranged from 1624 to $1905 \mathrm{HV}_{0,05}, 1702$ to $1948 \mathrm{HV}_{0,05}$, and 1745 to $2034 \mathrm{HV}_{0,05}$ respectively, whereas Vickers hardness values of the untreated steels GS18, GS22 and GS32 were $335 \mathrm{HV}_{0,05}, 358 \mathrm{HV}_{0,05}$ and $411 \mathrm{HV}_{0,05}$, respectively. The activation energies (Q) of borided steels were $228.644 \mathrm{~kJ} / \mathrm{mol}$ for GS18, $280.609 \mathrm{~kJ} / \mathrm{mol}$ for GS22 and $294.359 \mathrm{~kJ} / \mathrm{mol}$ for GS32. The growth kinetics of the boride layers forming on the GS18, GS22 and GS32 steels and the thickness of boride layers were also investigated.
\end{abstract}

Keywords. Boride layer; micro-hardness; kinetics; activation energy.

\section{Introduction}

Boriding is one of the thermochemical processes that has been developed and used recently in industries. In boriding process, boron atoms diffuse into the surface of the workpiece to produce hard boride layers without requiring high technology. The main advantage of this technique is that it leads to high strength of abrasion wear and high oxidation resistance compared with other conventional surface treatments (Campos et al 2003; Genel 2006; Efe et al 2008; Torun $\&$ Celikyurek 2009). The boriding process involves heating the material in the range of 973$1273 \mathrm{~K}$ during $1-12 \mathrm{~h}$, in contact with a boronaceus solid powder, paste, liquid, gaseous, plasma, plasma paste and fluidized bed boriding (Bektes et al 2010; Ulker et al 2011).

Boron atoms, because of their relatively small size and very mobile nature can diffuse into substrate material. Boron atoms, in general, dissolve in iron interstitially. Boron atoms due to their relatively small size and very mobile nature can diffuse easily into ferrous alloys forming 
$\mathrm{FeB}$ and $\mathrm{Fe}_{2} \mathrm{~B}$ intermetallic, non-oxide, ceramic borides. The diffusion of $\mathrm{B}$ into steel results in the formation of iron borides $\left(\mathrm{FeB}\right.$ and $\left.\mathrm{Fe}_{2} \mathrm{~B}\right)$ and the thickness of the boride layer is determined by the temperature and time of the treatment (Bindal \& Ucisik 1999; Ozdemir et al 2008). In industrial applications, a monolayer configuration $\left(\mathrm{Fe}_{2} \mathrm{~B}\right)$ is preferred over the bilayer configuration $\left(\mathrm{FeB}+\mathrm{Fe}_{2} \mathrm{~B}\right)$ due to the high intensity stress states generally situated at the $\left(\mathrm{FeB} / \mathrm{Fe}_{2} \mathrm{~B}\right)$ interface. The characteristics of this boride layer depend on the physical state of the boride source used, boriding temperature, treatment time, and properties of the borided material (Sahin \& Meric 2002; Campos-Silva et al 2009; Gunes et al 2011). Boriding of high carbon steels with high alloy content (like AISI D2) has been somewhat difficult in the past. Casteletti et al performed molten salt boriding of AISI D2 steel with borax $\left(\mathrm{Na}_{2} \mathrm{~B}_{4} \mathrm{O}_{7}\right)$ as the main active ingredient and ferrotitanium and aluminum as the reducing agents at $1073 \mathrm{~K}$ and $1273 \mathrm{~K}$ for $4 \mathrm{~h}$. They reported a maximum thickness of around $40 \mu \mathrm{m}$ (Casteletti et al 2009). In general, the presence of alloying elements reduces the diffusivity of boron in the steel and consequently decreases the thickness of the borided layer. For example, while carbon, molybdenum and tungsten dramatically reduce the borided layer thickness; silicon, chromium and aluminium have moderate influence, and nickel, manganese and cobalt have only marginal influence (Selcuk et al 2000). Studies are being performed with an aim to improve tribological performances of gear steels currently used in high-importance machine parts, especially in places exposed to wear. Surface modifications of these steels are a great focus of interest (Tabur et al 2009). GS18NiMoCr36, GS22NiMoCr56 and GS32NiCrMo6.4 gear steels are being commonly used in the industry that drive shafts, camshafts, pulleys, machine slide-ways, tanks, weapons and parts for agricultural machinery. In this study GS18NiMoCr36, GS22NiMoCr56 and GS32NiCrMo6.4 steels were borided considering these advantages of boriding. Characterization and growth diffusion of the obtained boride layer were calculated. The main objective of this study was to investigate the diffusion kinetics and the effect of process parameters, such as temperature, time and chemical composition, on the boride layers formed on steels GS18NiMoCr36, GS22NiMoCr56 and GS32NiCrMo6.4 after powder pack boriding at different processing temperatures and times.

\section{Experimental}

\subsection{Boriding and characterization}

Table 1 gives the composition of untreated GS18, GS22 and GS32 gear steels. The test specimens had a disc shape, with nominal dimensions of $25 \mathrm{~mm}$ in diameter and $8 \mathrm{~mm}$ of high, ground up to $1000 \mathrm{G}$ and polished using diamond solution. The boriding heat treatment was carried out in solid medium containing an Ekabor-II powder mixture placed in an electrical resistance furnace operated at temperatures of 1123, 1173 and $1223 \mathrm{~K}$ under atmospheric pressure. Test specimens were sealed in a stainless steel container together with the Ekabor II powder mixture. The holding times were 2, 4 and $6 \mathrm{~h}$ for each of the three steels. Following the completion of the boriding process, test specimens were removed from the sealed container and eventually allowed to cool

Table 1. The chemical composition of test materials (wt.\%).

\begin{tabular}{lcccccccc}
\hline Steels & $\mathrm{C}$ & $\mathrm{Si}$ & $\mathrm{Mn}$ & $\mathrm{P}$ & $\mathrm{S}$ & $\mathrm{Cr}$ & $\mathrm{Ni}$ & $\mathrm{Mo}$ \\
\hline GS18NiMoCr36 & 0.18 & 0.58 & 0.90 & 0.01 & 0.015 & 0.6 & 0.6 & 0.3 \\
GS22NiMoCr56 & 0.22 & 0.60 & 0.92 & 0.01 & 0.005 & 0.9 & 0.6 & 0.9 \\
GS32NiCrMo6.4 & 0.32 & 0.60 & 0.98 & 0.01 & 0.003 & 3.4 & 1.0 & 0.6 \\
\hline
\end{tabular}


down in still air. The microstructures of polished and etched cross-sections of the specimens were observed under an Olympus BX-60 optical microscope. The presence of borides formed in the coating layer was confirmed by means of X-ray diffraction equipment (Shimadzu XRD 6000) using $\mathrm{CuK} \alpha$ radiation. The distributions of alloying elements in the boride layer (which elements accumulated in boride teeth and between them) for GS18, GS22 and GS32 steels were determined by EDS (LEO 1430VP) from surface to interior. The thickness of borides was measured by means of a digital thickness measuring instrument attached to an optical microscope (Olympus BX60). Thickness values given in the results section are averages of at least 20 measurements. The contour diagrams, showing the variation in boride layer thickness with respect to the boriding temperature and time, were plotted using the Sigma plot 11.0 program. The hardness measurements of the boride layer on each steel and untreated steel substrate were made on the cross-sections using a Shimadzu HMV-2 Vickers indenter with a $50 \mathrm{~g}$ load.

\subsection{Kinetics}

On the condition that boron diffuses and grows parabolically, the alteration of boride layer thickness with time can be described by the following equation

$$
\mathrm{x}^{2}=\text { D.t, }
$$

where $\mathrm{x}$ is the depth of the boride layer $(\mathrm{mm}), \mathrm{t}$ is the boriding time $(\mathrm{s}), \mathrm{D}$ is the growth rate constant that depends on the diffusion element (in this case boron) and the diffusion coefficient. It is a well-known fact that the main factor limiting the growth of a layer is the diffusion of boron into the substrate. It is possible to argue that the relationship between growth rate constant, D, activation energy, Q, and the temperature in Kelvin, T, can be expressed as an Arrhenius equation:

$$
\mathrm{D}=\mathrm{Do} \cdot \exp (-\mathrm{Q} / \mathrm{RT}),
$$

where Do is a pre-exponential constant, $\mathrm{Q}$ is the activation energy $(\mathrm{J} / \mathrm{mol}), \mathrm{T}$ is the absolute temperature in Kelvin and $\mathrm{R}$ is the gas constant ( $\mathrm{J} / \mathrm{mol} \mathrm{K}$ ) (Tabur et al 2009; Meric et al 2000; Kayali et al 2012). The activation energy for the boron diffusion in the boride layer is determined by the slope obtained in the plot of $\mathrm{lnD}$ vs. $1 / \mathrm{T}$, using Eq. (2). The formation rate of the boride layers was examined and kinetic equations and parameters were determined at a temperature range of $1123-1223 \mathrm{~K}$ for periods of $2-6 \mathrm{~h}$.

\section{Results and discussion}

\subsection{Characterization of boride coatings}

The cross-section of optical micrographs of the borided GS18, GS22 and GS32 steels at temperatures of 1123,1173 and $1223 \mathrm{~K}$ for $6 \mathrm{~h}$ are shown in figures $1 \mathrm{a}-\mathrm{c}$. As can be seen in figures $1 \mathrm{a}-\mathrm{c}$, the boride layer formed on GS18, GS22 and GS32 steels have a saw-tooth morphology.

It was found that coating/matrix interface and matrix could be significantly distinguished and the boride layer had a columnar structure. In order to decide whether uniform boride layer thickness exists in all the samples, boriding temperature and holding time were monitored regarding the difference in columnar structures.

The coating thickness was influenced by alloying elements in the metal substrate $(\mathrm{C}, \mathrm{Cr}$, Mo, $\mathrm{Ni}$ ) which can modify the active boron diffusivity by entering the iron boride lattice. The amounts 


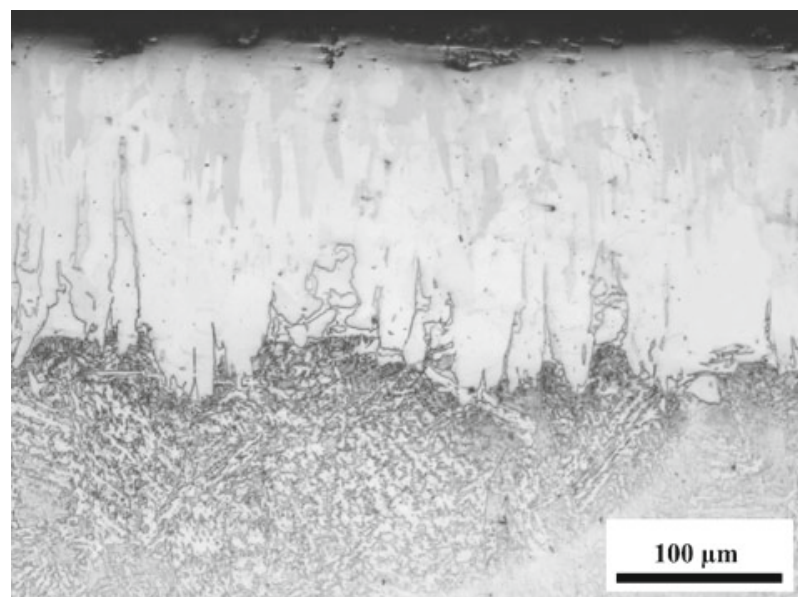

(a)

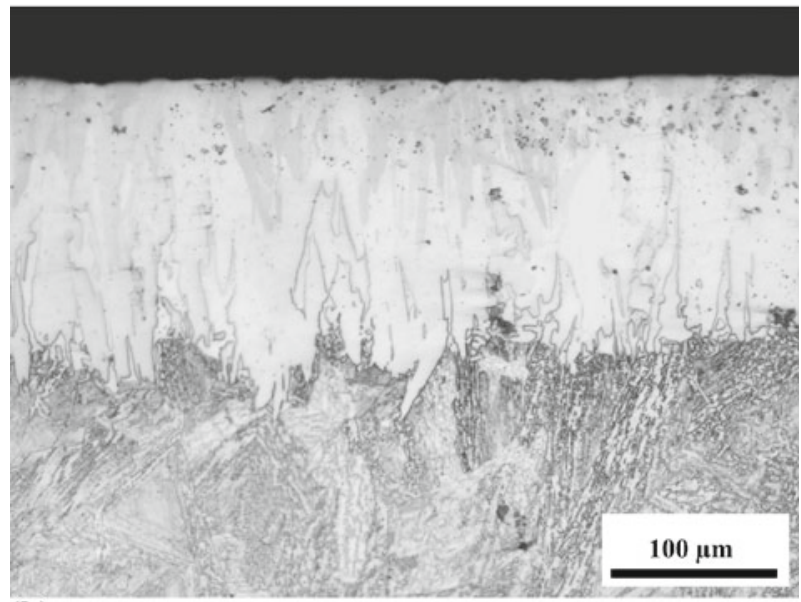

(b)

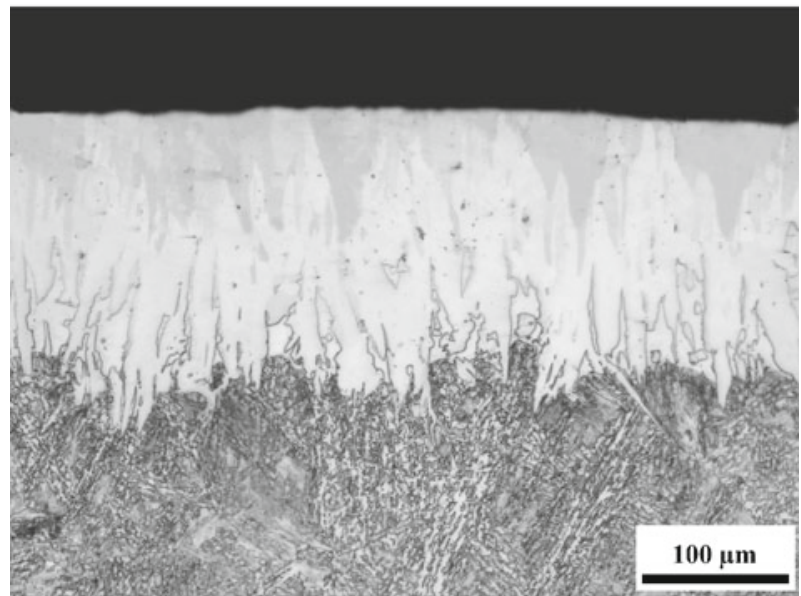

(c)

Figure 1. The cross-section of borided steels at $1223 \mathrm{~K}$ for $6 \mathrm{~h}$. (a) GS18, (b) GS22, (c) GS32. 
of $\mathrm{C}, \mathrm{Cr}$, Ni and Mo appear to be lower than that of iron in the boride layer because of less solubility. Thus, the deficiency of $\mathrm{C}, \mathrm{Cr}, \mathrm{Ni}$ and Mo results in a negative effect on the boride layer in terms of both thickness and morphology (Sinha 1991; Campos et al 2007; Pertek \& Kulka 2002; Ozbek \& Bindal 2011; Kartal et al 2011). Chromium and molybdenum preferentially enters the coatings by substituting for iron in the $\mathrm{FeB}$ and $\mathrm{Fe}_{2} \mathrm{~B}$. Nickel, and in turn, has a much lower tendency to dissolve in iron borides and concentrates in the base metal beneath the coating. Carbon, which is insoluble in iron borides, concentrates strongly at the interface with the coating (Taktak \& Tasgetiren 2006; Uslu et al 2007). Kayali et al (2012) borided AISI 440C steel with Ekabor 2 boron powder at $1123-1223 \mathrm{~K}$ for $2-8 \mathrm{~h}$ and obtained a $5.8-58 \mu \mathrm{m}$ boron layer. They determined that alloying elements had an effect on both the morphology and the thickness of the boron layer (Kayali et al 2012). Efe et al borided 31CrMoV9 and 34CrAlNi7 steels with Ekabor 2 boron powder at $1123-1223 \mathrm{~K}$ for $2-8 \mathrm{~h}$ and reported that some alloying elements $(\mathrm{Cr}$, $\mathrm{Ni}$ ) had a negative impact on the diffusion of boron atoms into the steel surface (Efe et al 2008).

\subsection{X-Ray diffraction analysis}

In this study, the presence of borides was identified using XRD analysis in figures $2 \mathrm{a}-\mathrm{c}$. XRD patterns show that the boride layer consists of borides such as $\mathrm{AB}$ and $\mathrm{A}_{2} \mathrm{~B}(\mathrm{~A}=\mathrm{Metal} ; \mathrm{Fe}, \mathrm{Cr})$. XRD results showed that boride layers formed on the GS18, GS22 and GS32 steels contained the $\mathrm{FeB}, \mathrm{Fe}_{2} \mathrm{~B}$ and $\mathrm{FeB}, \mathrm{Fe}_{2} \mathrm{~B}$ and $\mathrm{FeB}, \mathrm{Fe}_{2} \mathrm{~B}, \mathrm{CrB}, \mathrm{Cr}_{2} \mathrm{~B}$ phases, respectively in figures $2 \mathrm{a}-\mathrm{c}$. With increasing time and temperature, the $\mathrm{Fe}_{2} \mathrm{~B}$ phase content decreases and the $\mathrm{FeB}$ and $\mathrm{CrB}$ phases content increase for the GS32 steel. The boride layers mainly consist of intermetallic phases ( $\mathrm{FeB}$ and $\mathrm{Fe}_{2} \mathrm{~B}$ ) as a result of diffusion of boron atoms from the boriding compound to the metallic lattice with respect to the holding time. The properties of these boride layers are known to a large extent by the help of these phases (Yu et al 2005). The Gibbs free energy of the $\mathrm{Fe}_{2} \mathrm{~B}$ phase is more negative than that of the FeB phase, therefore, firstly, the $\mathrm{Fe}_{2} \mathrm{~B}$ phase and then the FeB phase is formed (Von Matuschka 1980). In the earlier studies conducted, it was determined that the $\mathrm{FeB}$ phase is formed as a result of the previously formed $\mathrm{Fe}_{2} \mathrm{~B}$ boron reacting with the boron in the medium (Knocke et al 1991; Barin \& Knocke 1973). Campos-Silva et al (2012) borided AISI 1045 and M2 steels at 1223-1273 K for 2 and 6 hours and found that the activation energy of the $\mathrm{Fe}_{2} \mathrm{~B}$ phase is lower than that of the FeB phase. Dybkov et al (2007) examined the growth rates of boride layers by boriding $\mathrm{Fe}-\mathrm{Cr}$ alloys. They reported that the growth rate of the $\mathrm{Fe}_{2} \mathrm{~B}$ phase is higher than that of $\mathrm{FeB}$ phase.

\subsection{Boride layer thickness and hardness}

The boride layer thickness changes depending on the boriding time and temperature are shown in figure 3. Boride layers on the surface of the GS18 steel ranged from 35.14 to $260.32 \mu \mathrm{m}$; from 20.45-204.52 $\mu \mathrm{m}$ on GS22 steel and from 15.68 to $175.81 \mu \mathrm{m}$ on GS32 steel. Depending on the process time, temperature and chemical composition of substrates, the depth of boride layer ranged from 15 to $260 \mu \mathrm{m}$ (figure 3). In this study, the highest boride layer was obtained in GS18 steel, while the lowest boride layer was obtained in GS32 steel. The boride layer thickness increases with increasing boriding time and temperature for each steel. As result of the boriding process, boride layer thickness increases with increasing boriding temperature, time, and depending on the chemical composition of steels.

Contour diagrams showing boride layer variations due to boriding temperature and time are given in figures $4 \mathrm{a}-\mathrm{c}$. Contour diagrams can be used for two purposes: (i) to predict the coating layer thickness with respect to the process parameters, namely time and temperature. (ii) To 

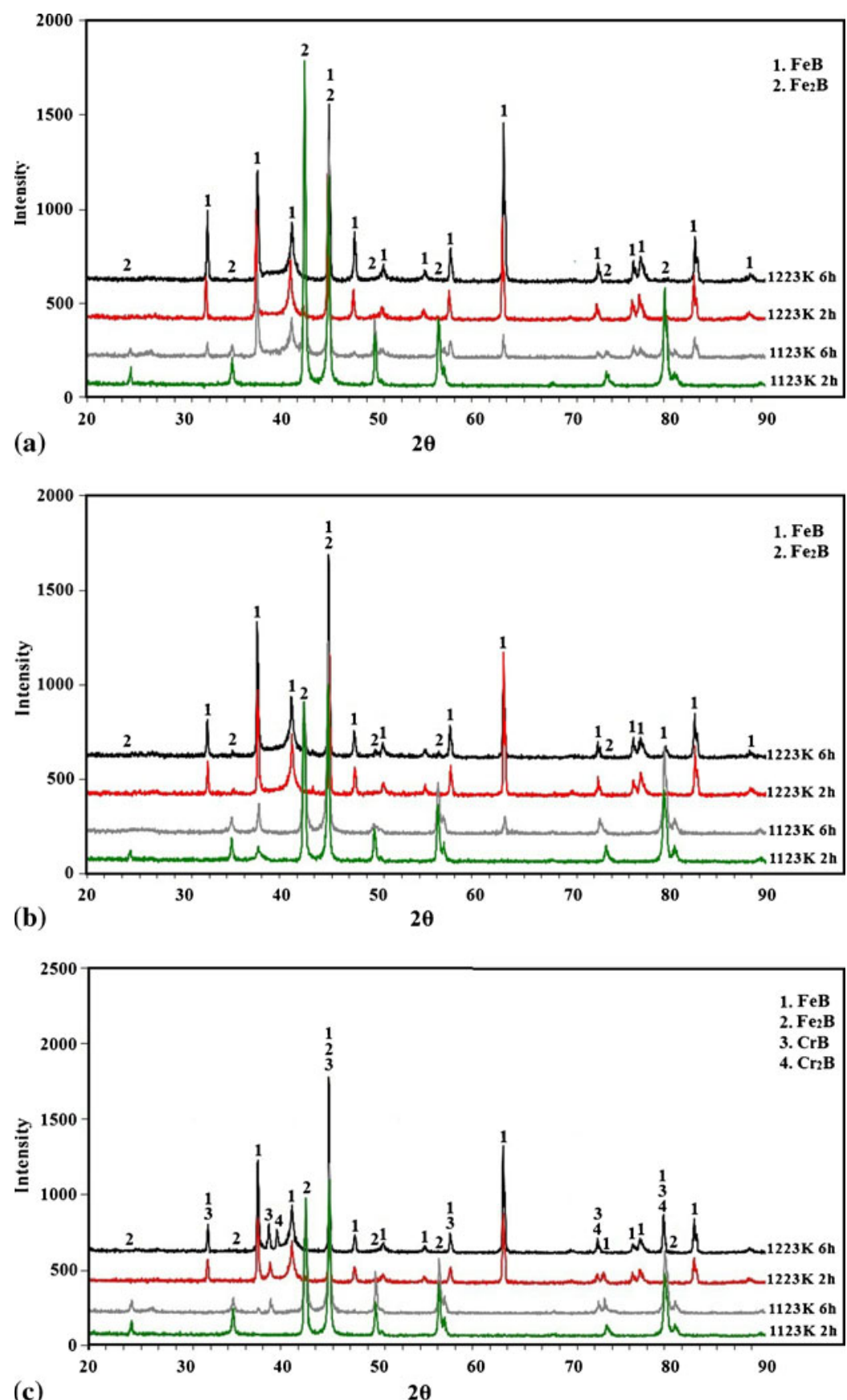

Figure 2. X-ray diffraction patterns of borided steels at 1123 and $1223 \mathrm{~K}$ for 2 and $6 \mathrm{~h}$. (a) GS18, (b) GS22, (c) GS32. 


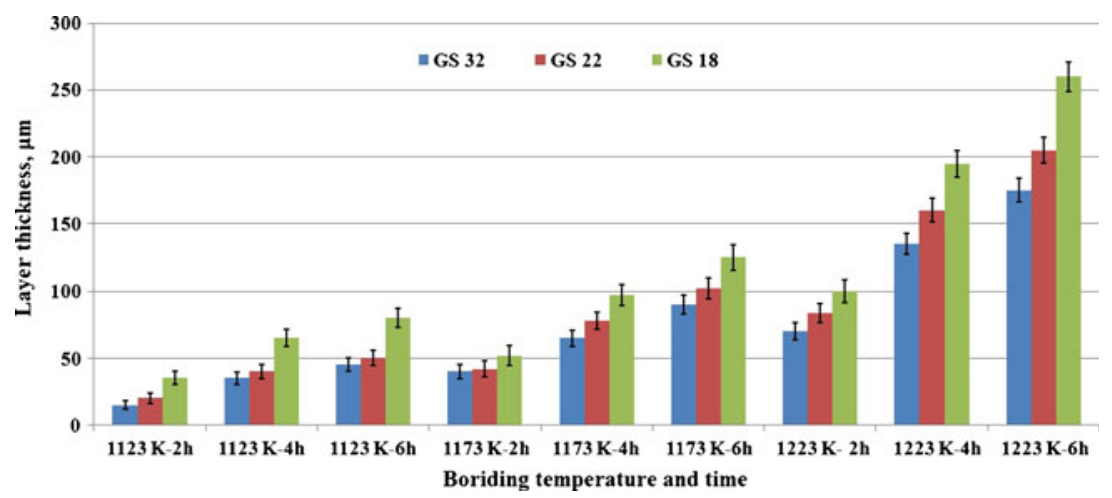

Figure 3. The thickness values of boride layers with respect to boriding time and temperatures.

determine the value of process time and temperature for obtaining a predetermined coating layer thickness (Ozdemir et al 2008; Sen et al 2005a, b). The boride layer increased with the increase in boriding time and temperature in GS18, GS22 and GS32 steels.

EDS line analysis was performed to determine which element accumulated among the FeB phase and matrix in the steels, (figures $5 \mathrm{a}-\mathrm{c}$ ). In this region, $\mathrm{Fe}, \mathrm{Cr}$ and small scales of $\mathrm{Si}$ were determined. This might be indicated by FeB and $\mathrm{CrB}$ phases, determined by an XRD pattern, in the outer layer of the boride coating. EDS analysis showed that iron concentration in the boride layer was lower in the outer layer of the boride coating than in the inner part. These observations were confirmed by the EDS analysis (figures $5 \mathrm{a}-\mathrm{c}$ ).

Micro-hardness measurements were done from the surface to the interior along a line to see variation of hardness of the boride layer, transition zone and matrix, respectively. Micro-hardness of the boride layers was measured at 12 different locations at the same distance from the surface and the average value was taken as the hardness. Micro-hardness measurements were carried out on the cross-sections from the surface to the interior along a line; see figures $6 \mathrm{a}-\mathrm{c}$. The hardness of the boride layer formed on the GS18 steel varied between 1624 and $1905 \mathrm{HV}_{0,05}$ the hardness of the boride layer on the GS22 steel varied between 1702 to $1948 \mathrm{HV}_{0,05}$, and the hardness of the boride layer on the GS32 steel varied between 1745 and $2034 \mathrm{HV}_{0,05}$, respectively. On the other hand, Vickers hardness values were $335 \mathrm{HV}_{0,05}, 358 \mathrm{HV}_{0,05}$ and $411 \mathrm{HV}_{0,05}$, for the untreated GS18, GS22 and GS32 gear steels, respectively. When the hardness of the boride layer is compared with the matrix, boride layer hardness is approximately five times greater than that of matrix.

\subsection{Kinetics}

In this study, the effects of the processing temperature and boriding time on the growth kinetics of the boriding layer were also investigated. Kinetic parameters such as processing temperature and time must be known for the control of the boriding treatment and the growth rate constants were calculated using Eq. (1) (figure 7).

As a result, it is possible to say that diffusion rate of boron atoms perpendicular to surface of GS18 steel is higher than that of GS32 steel. The effective growth rate constants with respect to boriding temperature are $11.3 \times 10^{-11}, 56.3 \times 10^{-11}$, and $106.2 \times 10^{-11} \mathrm{~cm}^{2} \mathrm{~s}^{-1}$ for the GS18 steel, $2.24 \times 10^{-11}, 9.43 \times 10^{-11}$ and $36.59 \times 10^{-11} \mathrm{~cm}^{2} \mathrm{~s}^{-1}$ for the GS22 steel and $0.74 \times$ $10^{-11}, 3.23 \times 10^{-11}, 12.44 \times 10^{-11} \mathrm{~cm}^{2} \mathrm{~s}^{-1}$ for the GS32 steel, respectively (table 2 ). The 

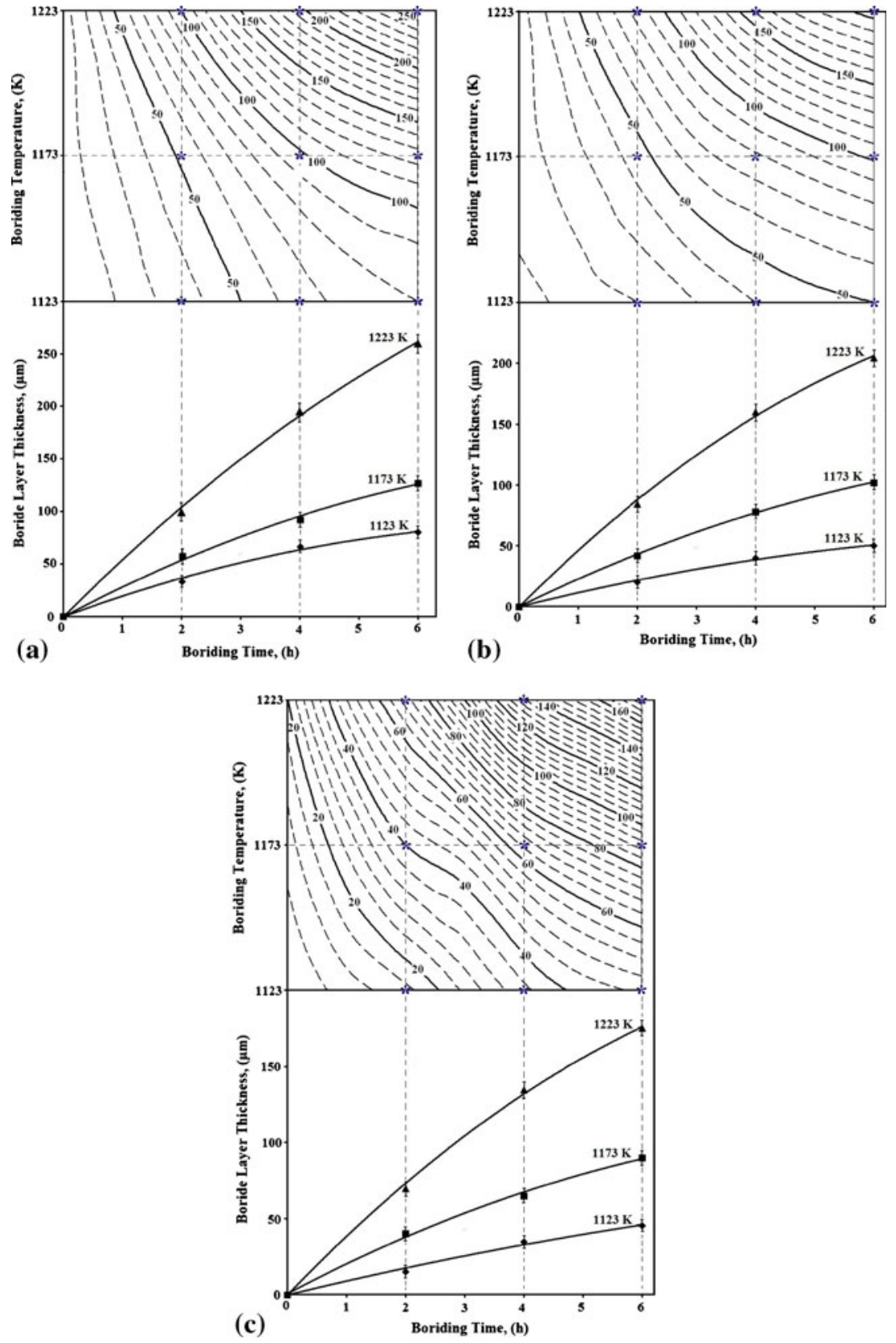

Figure 4. The contour diagram and the thickness values of boride layers with respect to holding time and test temperatures. (a) GS18, (b) GS22 and (c) GS32.

calculated growth rate constant of GS18 is higher than that of GS32 due to its lower alloying element content. This indicates that borides on the surface of the GS18 steel forms easier and grows quicker compared to GS32 steel. 

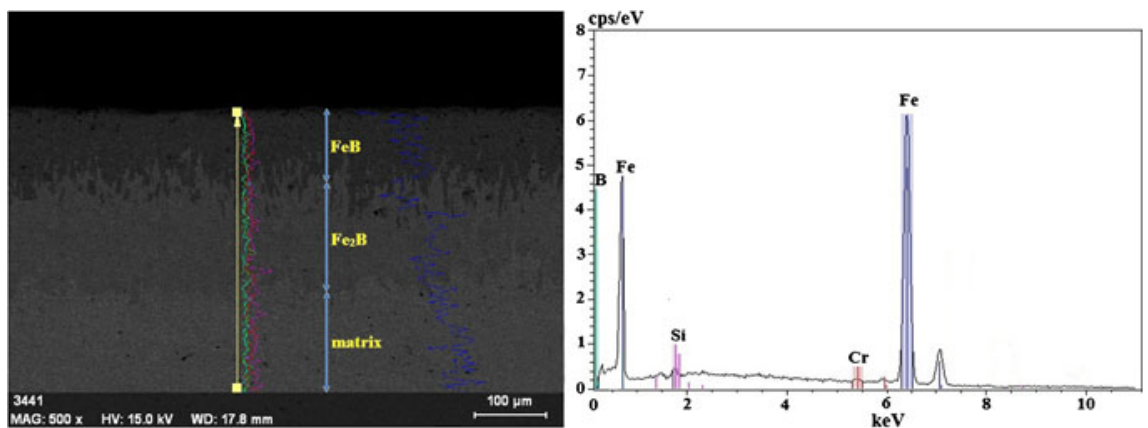

(a)
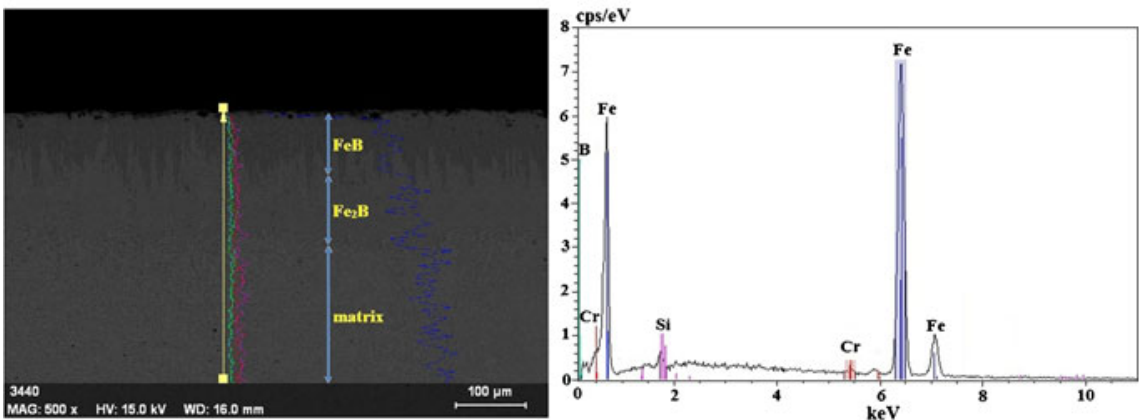

(b)
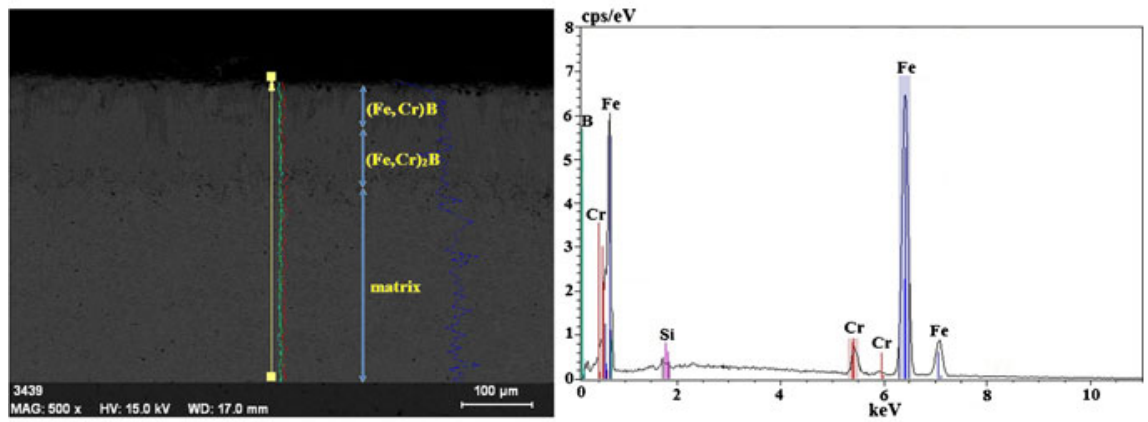

(c)

Figure 5. Energy dispersive X-ray spectroscopy (EDS) line scan analyses of a sample borided at $1223 \mathrm{~K}$ for 6 h. (a) GS18, (b) GS22 and (c) GS32.

The plot of $\mathrm{LnD}$ versus $1 / \mathrm{T}$ exhibits a linear relationship (figure 8) and the activation energy of $228.644 \mathrm{~kJ} / \mathrm{mol}$ for the GS18 steel, $280.609 \mathrm{~kJ} / \mathrm{mol}$ for the GS22 steel and $294.359 \mathrm{~kJ} / \mathrm{mol}$ for the GS32 steel were obtained from the slope of the straight lines. The calculated activation energy value for GS32 is higher than that of GS18 and GS22 steels due to its high alloying element content. Consequently, diffusion rate of boron atoms perpendicular to surface of GS18 is higher than that of GS32. The lower activation energy is obtained in the longer layer thickness (Uslu et al 2007).

Activation energy values obtained in this study vary in accordance with the chemical composition of steels. In steels with low alloying elements such as GS18, activation energy decreases with the boride layer thickness increases at the boriding treatment. The values calculated in this 


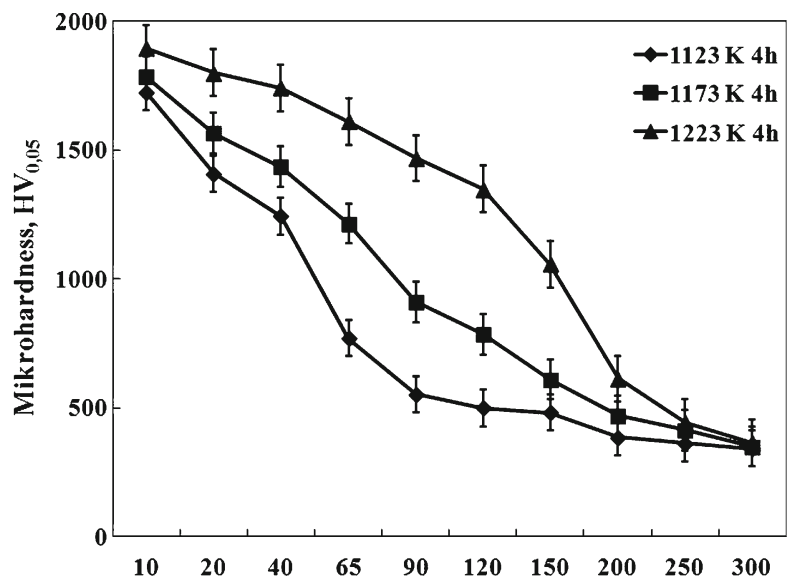

(a)

Distance from the surface, $\mu \mathrm{m}$
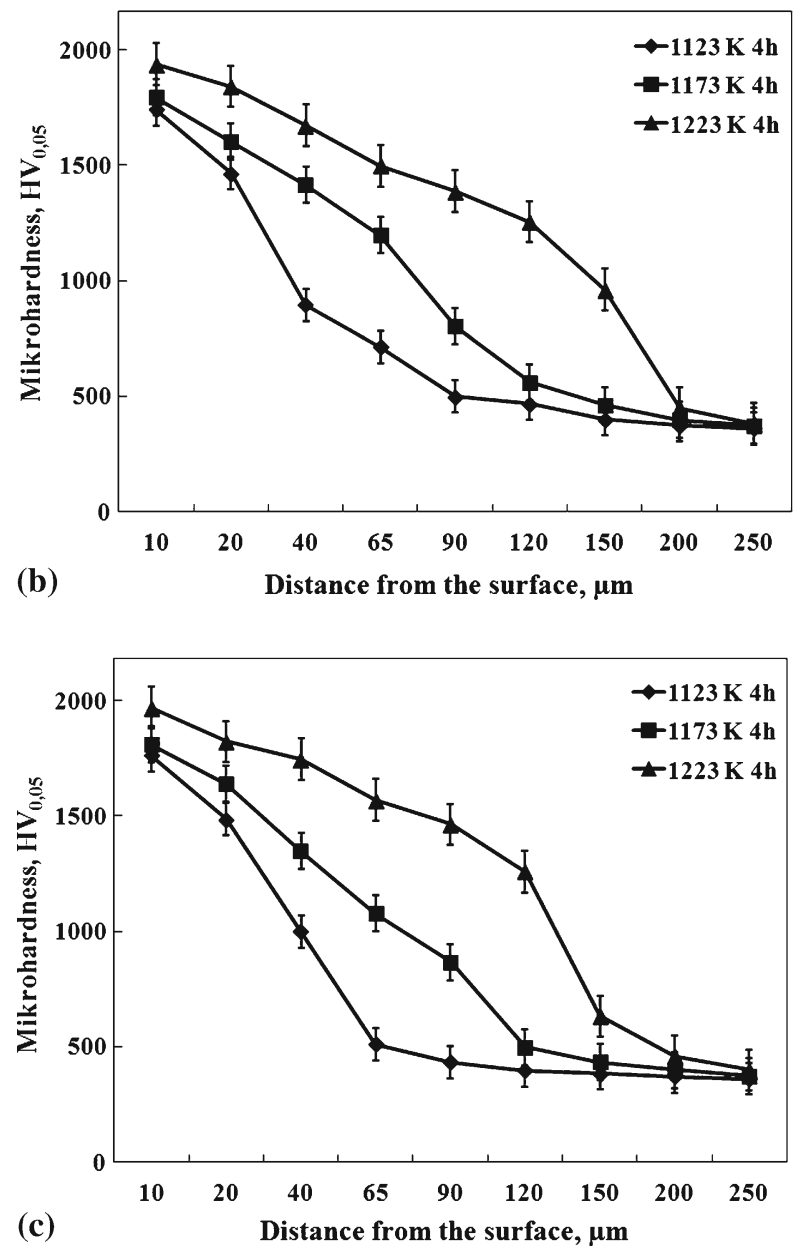

Figure 6. The variation of hardness depth in GS18. (a), GS22 (b), and GS32 (c) steels borided at 1123, 1173 and $1223 \mathrm{~K}$ for $4 \mathrm{~h}$. 


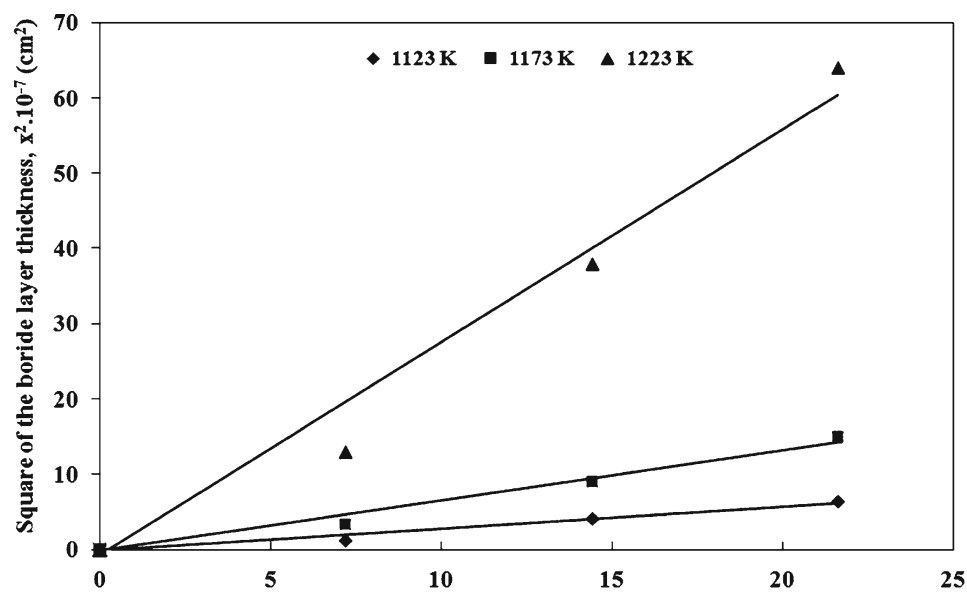

(a)

Boriding time, t. $10^{3}(\mathrm{sn})$

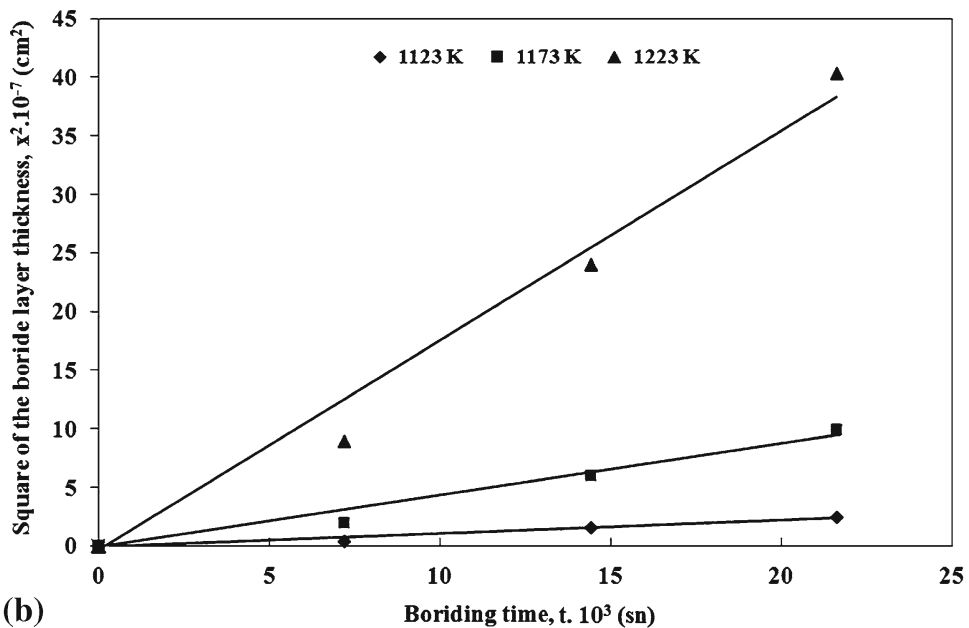

(b)

Boriding time, t. $10^{3}(\mathrm{sn})$

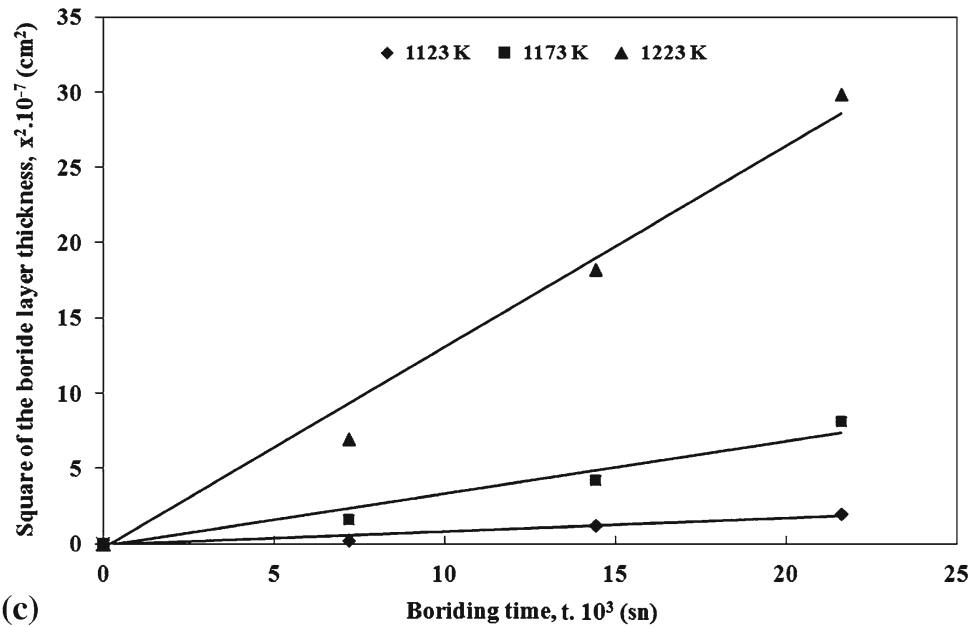

Figure 7. Square of the boride layer thickness vs. holding time in steels GS18 (a), GS22 (b) and GS32 (c). 
Table 2. Growth rate constant (D) and activation energy (Q) as a function of boronizing temperature and steel.

\begin{tabular}{lcccc}
\hline & \multicolumn{3}{c}{ Growth rate constant $\left(\mathrm{cm}^{2} \mathrm{~s}^{-1}\right)$} \\
\cline { 2 - 4 } & \multicolumn{3}{c}{ Temperature, $\mathrm{K}$} & \\
\cline { 2 - 4 } Steels & $1123 \mathrm{~K}$ & $1173 \mathrm{~K}$ & $1223 \mathrm{~K}$ & $\begin{array}{c}\text { Activation } \\
\text { energy }(\mathrm{kJ} / \mathrm{mol})\end{array}$ \\
\hline GS18NiMoCr36 & $11.3 \times 10^{-11}$ & $56.3 \times 10^{-11}$ & $106.2 \times 10^{-11}$ & 228.644 \\
GS22NiMoCr56 & $2.24 \times 10^{-11}$ & $9.43 \times 10^{-11}$ & $36.59 \times 10^{-11}$ & 280.609 \\
GS32NiCrMo6.4 & $0.74 \times 10^{-11}$ & $3.23 \times 10^{-11}$ & $12.44 \times 10^{-11}$ & 294.359 \\
\hline
\end{tabular}

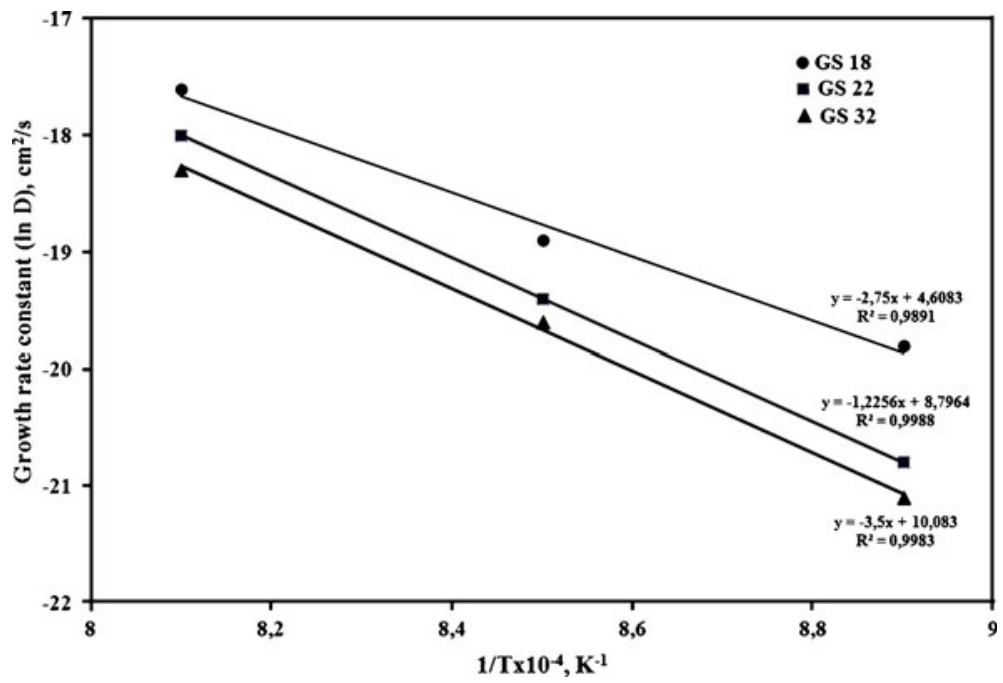

Figure 8. The growth rate constant vs. the processing temperature in the GS18, GS22 and GS32 steels.

Table 3. The comparison of activation energy for diffusion of boron with respect to the different boriding medium and steel.

\begin{tabular}{lcccl}
\hline Steel & $\begin{array}{c}\text { Temperature } \\
\text { range }(\mathrm{K})\end{array}$ & $\begin{array}{c}\text { Boriding } \\
\text { medium }\end{array}$ & $\begin{array}{c}\text { Activation } \\
\text { energy }(\mathrm{kJ} / \mathrm{mol})\end{array}$ & References \\
\hline AISI W1 & $1123-1323$ & Salt bath & 171 & (Genel et al 2003) \\
AISI 4140 & $1123-1223$ & Solid & 215 & (Sen et al 2005a, b) \\
AISI 304 & $1073-1223$ & Salt bath & 253 & (Taktak 2006) \\
H13 & & & 244 & (Yoon et al 1999) \\
AISI 304 & $1023-1223$ & Plasma paste & 123 & Present study \\
GS18NiMoCr36 & $1123-1223$ & Solid & 228 & \\
GS22NiMoCr56 & & & 280 & \\
GS32NiCrMo6.4 & & & 294 & \\
\hline
\end{tabular}


study are comparable with the values reported in the literature as seen in table 3 (Uslu et al 2007; Yu et al 2002; Genel et al 2003; Sen et al 2005a, b; Taktak 2006). Although the rate of alloying element of the steel (AISI 304) borided especially with Yoon et al (1999) and Taktak (2006) are higher than that of the gear steels used in this study, the activation energy required for the boriding process turned out to be low. The present study gives the highest activation energy. It can be considered that alloying elements acted as a diffusion barrier, inhibiting the diffusion of active boron.

\section{Conclusions}

The following conclusions may be derived from the present study.

(i) Boride types formed on the surface of the GS18, GS22 and GS32 steels have saw tooth morphology.

(ii) Depending on the process time, temperature and chemical composition of substrates the depth of the boride layer ranged from 15 to $265 \mu \mathrm{m}$.

(iii) The multiphase boride coatings that were thermo chemically grown on the GS18, GS22 and GS32 steels were constituted by the $\mathrm{FeB}, \mathrm{Fe}_{2} \mathrm{~B}$ and $\mathrm{FeB}, \mathrm{Fe}_{2} \mathrm{~B}$ and $\mathrm{FeB}, \mathrm{Fe}_{2} \mathrm{~B}, \mathrm{CrB}$, $\mathrm{Cr}_{2} \mathrm{~B}$ phases, respectively.

(iv) The distribution of alloying elements was determined by EDS and it was found that $\mathrm{Cr}$ preferentially enters the coatings by substituting for iron in the $\mathrm{FeB}$ and $\mathrm{Fe}_{2} \mathrm{~B}$.

(v) The thickness of the boride layer formed on the surface of the GS32 and GS22 steels is lower than that of the GS18 steel. The boride layer thickness decreased by increasing the amount of carbon and alloying elements in GS32 steels.

(vi) The surface hardness of the borided GS18 steel was in the range of 1624-1905 $\mathrm{HV}_{0,05}$, while for the untreated GS18 steel substrate, it was $335 \mathrm{HV}_{0,05}$. The surface hardness of the borided GS22 steel was in the range of 1702-1948 $\mathrm{HV}_{0,05}$, while for the untreated GS22 steel substrate it was $358 \mathrm{HV}_{0,05}$. The surface hardness of the borided GS32 steel was in the range of 1745-2034 $\mathrm{HV}_{0,05}$, while for the untreated GS32 steel substrate it was $411 \mathrm{HV}_{0,05}$.

(vii) Activation energy of $228.644 \mathrm{~kJ} / \mathrm{mol}$ for GS18, $280.609 \mathrm{~kJ} / \mathrm{mol}$ for GS22 and $294.359 \mathrm{~kJ} / \mathrm{mol}$ for GS32 steels were determined. It may be said that the diffusivity of B atoms in GS32 is lower than that of GS18 due to the alloying elements it possesses.

(viii) The growth acceleration of borides in GS18 is higher than that of the GS22 and GS32 steels and increases with increasing temperature.

\section{References}

Barin I and Knocke O 1973 Thermo-chemical properties of inorganic substances, 1. Edition, Berlin Heidelberg, New York: Springer-Verlag

Bektes M, Calik A, Ucar N and Keddam M 2010 Pack-boriding of Fe-Mn binary alloys: characterization and kinetics of the boride layers. Mater. Charact. 61: 233-239

Bindal C and Ucisik A H 1999 Characterization of borides formed on impurity-controlled chromium-based low alloy steels. Surf. Coat. Technol. 122: 208-213

Campos I, Oseguera J, Figueroa U, Garc1 J A, Bautista O and Kelemenis G 2003 Kinetic study of boron diffusion in the paste-boriding process. Mater. Sci. Eng. A 352: 261-265

Campos I, Ramirez G, Figueroa U, Martinez J and Morales O 2007 Evaluation of boron mobility on the phases $\mathrm{FeB}, \mathrm{Fe}_{2} \mathrm{~B}$ and diffusion zone in AISI 1045 and M2 steels. Appl. Surf. Sci. 253: 3469-3475 
Campos-Silva I, Ortiz-Dominguez M, Keddam M, Lopez-Perrusquia N, Carmona-Vargas A and EliasEspinosa M 2009 Kinetics of the formation of $\mathrm{Fe}_{2} \mathrm{~B}$ layers in gray cast iron: effects of boron concentration and boride incubation time. Appl. Surf. Sci. 255: 9290-9295

Campos-Silva I, Ortiz-Dominguez M, Tapia-Quintero C, Rodriguez-Castro G, Jimenez-Reyes M Y and Chavez-Gutierrez E 2012 Kinetics and boron diffusion in the $\mathrm{FeB} / \mathrm{Fe}_{2} \mathrm{~B}$ layers formed at the surface of borided high-alloy steel. J. Mater. Eng. Perform. 21: 1714-1723

Casteletti L C, Fernandes F A P, Heck S C, Oliveira C K N, Neto A and Totten G E 2009 Pack and salt bath diffusion treatments on steels. Heat Treat. Prog. 9: 49-52

Dybkov V I, Goncharuk L V, Khoruzha V G, Meleshevich K A, Samelyuk A V and Sidorko V R 2007 Growth kinetics of boride layers on iron-chromium alloys and their dry abrasive wear resistance, Materials Science \& Technology Conference and Exhibition, Sep 2007, 1812-1823

Efe G C, Ipek M, Ozbek I and Bindal C 2008 Kinetics of borided 31CrMoV9 and 34CrAlNi7 steels. Mater. Charact. 59: 23-31

Genel K 2006 Boriding kinetics of H13 steel. Vacuum 80: 451-457

Genel K, Ozbek I and Bindal C 2003 Kinetics of boriding of AISI W1 steel. Mater. Sci. and Eng. A 347: 311-314

Gunes I, Ulker S and Taktak S 2011 Plasma paste boronizing of AISI 8620, 52100 and 440C steels. Mater. and Des. 32: 2380-2386

Kartal G, Eryilmaz O L, Krumdick G, Erdemir A and Timur S 2011 Kinetics of electrochemical boriding of low carbon steel. Appl. Surf. Sci. 257: 6928-6934

Kayali Y, Gunes I and Ulu S 2012 Diffusion kinetics of borided AISI 52100 and AISI 440C steels. Vacuum 86: $1428-1434$

Knocke O, Kubaschewski O and Hesselmann K 1991 Thermo-chemical properties of inorganic substances, 2. Edition, Berlin Heidelberg, New York: Springer-Verlag

Meric C, Sahin S and Yilmaz S S 2000 Investigation of the effect on boride layer of powder particle size used in boronizing with solid boron-yielding substances. Mater. Res. Bull. 35: 2165-2172

Ozbek I and Bindal C 2011 Kinetics of borided AISI M2 high speed steel. Vacuum 86: 391397

Ozdemir O, Omar M A, Usta M, Zeytin S, Bindal C and Ucisik A H 2008 An investigation on boriding kinetics of AISI 316 stainless steel. Vacuum 83: 175-179

Pertek A and Kulka M 2002 Characterization of complex $(B+C)$ diffusion layers formed on chromium and nickel-based low-carbon steel. Appl. Surf. Sci. 202: 252-260

Sahin S and Meric C 2002 Investigation of the effect of boronizing on cast irons. Mater. Res. Bull. 37: 971-979

Selcuk B, Ipek R, Karamis M B and Kuzucu V 2000 An investigation on surface properties of treated low carbon and alloyed steels. J. Mater. Process. Technol. 103: 310-317

Sen S, Sen U and Bindal C 2005a An approach to kinetic study of borided steels. Surf. Coat. Technol. 191: 274-285

Sen S, Sen U and Bindal C 2005b The growth kinetics of borides formed on boronized AISI 4140 steel. Vacuum 77: 195-202

Sinha A K 1991 Boriding (Boronizing) ASM handbook. J. Heat Treat. 4: 437-447 [OH, USA]

Tabur M, Izciler M, Gul F and Karacan I 2009 Abrasive wear behavior of boronized AISI 8620 steel. Wear 266: 1106-1112

Taktak S 2006 A study on the diffusion kinetics of borides on boronized Cr-based steels. J. Mater. Sci. 41: $7590-7596$

Taktak S and Tasgetiren S 2006 Identification of delamination failure of boride layer on common Cr-based steels. J. Mater. Eng. Perform. 15: 570-574

Torun O and Celikyurek I 2009 Boriding of diffusion bonded joints of pure nickel to commercially pure titanium. Mater. Des. 30: 1830-1834

Ulker S, Gunes I and Taktak S 2011 Investigation of tribological behaviour of plasma paste boronized of AISI 8620, 52100 and 440C steels. Indian J. Eng. Mater. Sci. 18: 370-376 
Uslu I, Comert H, Ipek M, Ozdemir O and Bindal C 2007 Evaluation of borides formed on AISI P20 steel. Mater and Des. 28:55-61

Von Matuschka A G 1980 Boronizing, Philadelphia: Heyden and Son Inc.

Yoon J H, Jee Y K and Lee S Y 1999 Plasma paste boronizing treatment of the stainless steel AISI 304. Surf Coat Technol. 112: 71-75

Yu L G, Chen X J, Khor K A and Sundararajan G $2005 \mathrm{FeB} / \mathrm{Fe}_{2} \mathrm{~B}$ phase transformation during SPS packboriding: boride layer growth kinetics. Acta Mater. 53: 2361-2368

Yu L G, Khor K A and Sundararajan G 2002 Boriding of mild steel using the spark plasma sintering (SPS) technique. Surf Coat Technol. 157: 226-230 